\title{
IMPLEMENTASI ALGORITMA WEIGHTED PRODUCT UNTUK PENCARIAN KARYAWAN TERBAIK
}

\author{
Esa Ahara Putra, Subandi \\ Program Studi Teknik Informatika, Universitas Budi Luhur \\ J1. Ciledug Raya, Jakarta Selatan \\ esa ahara@yahoo.com, subandi@budiluhur.ac.id
}

\begin{abstract}
In a company the most important and fundamental thing is the human resources it possesses. The success or success of a company depends on how the company manages the human resources. The selection of the best employees is done to spur the spirit of employees in increasing loyalty or loyalty of employees to the company and to evaluate the performance of employees of each division is indispensable. The selection of the best employees at the time of research is done with the calculation process that still uses Microsoft Excel and simple calculations so sometimes there are errors in the calculation. To solve the assessment process problems than using a method weighted product that implemented into an application. So the results of the output in this research a result of the calculation of each employee.
\end{abstract}

Keywords - Employees, Elections, Resources, Assessments.

Abstrak - Dalam sebuah perusahaan hal yang paling penting dan mendasar adalah sumber daya manusia yang dimilikinya. Karena letak keberhasilan atau kesuksesan sebuah perusahaan tergantung bagaimana perusahaan tersebut mengelola Sumber Daya Manusia. Pemilihan karyawan terbaik dilakukan untuk memacu semangat karyawan dalam meningkatkan loyalitas atau kesetiaan karyawan kepada perusahaan dan untuk mengevaluasi kinerja karyawan dari setiap divisi sangat diperlukan. Pemilihan karyawan terbaik pada saat penelitian dilakukan dengan proses perhitungan yang masih menggunakan microsoft excel dan perhitungan yang sederhana sehingga terkadang terjadi kesalahan dalam perhitungan. Untuk mengatasi permasalahan proses penilaian tersebut maka digunakan sebuah metode weighted product yang diimplementasikan kedalam sebuah aplikasi. Sehingga hasil keluaran dalam penelitian ini sebuah perangkingan hasil dari perhitungan tiap-tiap karyawan.

Kata kunci - Karyawan, Pemilihan, Sumber Daya, Penilaian.

\section{PENDAHULUAN}

Keberhasilan pada suatu organisasi ditentukan dengan adanya sebuah mutu atau kualitas pada sumber daya manusia. Sumber Daya Manusia ini merupakan salah satu faktor penting penentu berhasil dan gagalnya suatu organisasi atau unit kerja dalam pencapaian kinerja [1] Kinerja adalah hasil sebuah kerja yang mendapatkan mengakuan atas prestasi kerja atau dapat dikatakan pekerjaan yang berkualitas baik itu jika dinilai dari segi kuantitas atau kualitas yang dikerjakan oleh sumber daya manusia pada periode waktu yang diberikan dan sesuai dengan tanggung jawab yang dibebankan kepadanya. [2]. Untuk meningkatkan kinerja pada sebuah organisasi atau perusahaan maka seorang karyawan diberikan sebuah reward atau penghargaan jika kinerjanya benar-benar maksimal. sebuah bentuk penghargaan yang menilai atas dasar kinerja adalah sebuah bentuk alat pengendalian yang paling penting pada perusahaan, hal tersebut berguna untuk memacu semangat kerja pada karyawan agar target atau tujuan perusahaan dapat tercapai [3]. Pada saat penelitian proses perhitungan masih menggunakan microsoft excel dan perhitungan yang sederhana sehingga terkadang terjadi kesalahan dalam perhitungan. Sehingga pihak pengambil keputusan terkadang salah dalam memilih karyawan terbaik. Untuk mengatasi permasalahan dalam proses perhitungan dan pemilihan karyawan terbaik tersebut maka peneliti menggunakan sebuah metode atau algoritma yaitu weighted product. Penelitian serupa juga telah dilakukan oleh Atep dan sulaiman [4] yang meneliti tentang penilaian kinerja karyawan pada PT. Infomedia solusi humanika menggunakan algoritma weighted product. pada penelitian tersebut menggunakan 5 kriteria yaitu kehadiran, produktifitas, integritas, skill dan loyalitas. permasalahan yang dihadapi pada penelitian tersebut adalah proses penilaian yang menggunakan microsoft excel sehingga penilaian tidak objectif dan manajer hrd keliru dalam menilai karyawan terbaik. hasil dari penelitian tersebut adalah sebuah aplikasi yang sudah menggunakan algoritma weighted product

\section{METODE PENELITIAN}

\section{A. Metode Pengumpulan Data}

Metode pengumpulan data digunakan untuk mengumpulan sumber-sumber data yang akan digunakan untuk membangun sebuah aplikasi sistem penunjang keputusan, adapun metode yang digunakan dalam penelitian ini yaitu langkah pertama adalah mewawancari kepala Human Resource Development, adapun proses wawancara tersebut dilaksanakan agar peneliti dapat melihat dan memahami proses bisnis 
serta prosedur-prosedur terkait dengan aplikasi yang akan dibuat, sehingga aplikasi dapat berjalan sesuai dengan keinginan dan kebutuhan dari pihak pengambil keputusan terkait pemilihan karyawan terbaik. Adapun pada saat proses Observasi dilakukan dengan melihat langsung proses pemilihan karyawan terbaik baik pada saat proses perhitungan sampai dengan proses perangkingan. Dan pada studi literatur dilaksanakan dengan cara mempelajari jurnal-jurnal, buku-buku dan referensi lainnya yang terkait dengan permasalahan penelitian.

\section{B. Metode pemilihan karyawan terbaik menggunakan algoritma Weighted Product}

Dalam penelitian ini metode Weighted Product digunakan untuk karyawan terbaik yang berhak mendapatkan reward. Adapun langkah-langkah Weighted Product yang digunakan dalam memilih karyawan terbaik antara lain [5] :

a. Melakukan identifikasi kriteria yang hendak digunakan serta memberikan nilai pada bobot kepentingan masing-masing kriteria.

b. Melakukan proses range nilai pada masing-masing kriteria beserta penilaian alternatif yang hendak dipilih.

c. Proses Normalisasi (Perbaikan Bobot) dengan formula seperti pada formula (1)

$$
W_{j=\frac{W_{j}}{\Sigma W_{j}}}
$$

Adapun tujuan dari proses normalisasi dilakukan untuk menghasilkan nilai $\mathrm{W}_{\mathrm{j}}=1$, dimana nilai ${ }_{\mathrm{j}}=1,2,3, \ldots$, $\mathrm{n}$ adalah jmlah dari banyaknya alternatif yang akan dipilih, sedangkan $\Sigma$ adalah nilai dari jumlah seluruh nilai bobot yang digunakan.

d. Mencari Nilai dari sebuah Vektor (S) dengan formula seperti pada formula (2)

$$
S_{i}=\prod_{j}^{n}=1 X_{i j} W^{j}
$$

dimana $i=1,2,3, \ldots, n$

untuk mencari nilai vektor (S) dilakukan dengan cara mengalikan keseluruhan nilai yang ada pada kriteria dengan nilai yang ada pada alternatif. hasil dari normalisasi yang berpangkat jenis positif untuk kriteria benefit sedangkan yang berpangkat jenis negatif untuk kriteria cost.

Untuk nilai (S) adalah preferensi dari masing-masing kriteria, sedangkan (X) adalah nilai pada tiap-tiap kriteria dan (n) adalah jumlah banyaknya kriteria yang digunakan.

e. Mencari nilai dari sebuah Vektor (V) dengan formula seperti pada formula (3)

$V_{i}=\frac{s_{i}}{\Sigma s_{i}}$

dimana $i=1,2,3, \ldots, n$

untuk mencari sebuah nilai vektor (V) yang hendak digunakan untuk proses perangkingan dari tiap-tiap jumlah nilai pada vektor (S) dilakukan dengan cara menjumlahkan seluruh nilai pada vektor (S) yang didapat dari preferensi masing-masing alternatif.

\section{Metode Pengambilan Sample}

Pada metode Pengambilan sample menggunakan metode purposive sampling yaitu pengambilan sebuah sampel pada sumber data dilakukan dengan pertimbangan tertentu [6]. pada saat proses pemilihan karyawan terbaik dengan sampel sebanyak 5 orang karyawan.

\section{Metode Analisa}

Adapun metode analisa yang digunakan adalah Unified Modeling Language atau UML dan yang digunakan hanya sebatas use case beserta class diagram. Suatu sistem agar dapat berjalan dengan lancar dan sesuai kebutuhan requirement maka perlu dilakukan sebuah analisis yang tepat [7].

\section{HASIL DAN PEMBAHASAN}

\section{A. Pembahasan Metode Weighted Product}

Simulasi Sample Perangkingan Menggunakan Metode Weighted Product Proses penentuan karyawan terbaik menggunakan metode weighted product adalah sebagai berikut :

a. Menentukan alternatif karyawan yang akan dipilih sebagai karyawan terbaik. Dalam pengujian ini menggunakan data karyawan sebanyak 5 orang karyawan. Adapun data karyawan tersebut yaitu :

A1 = Karyawan 1 (Alternatif ke 1)

A2 $=$ Karyawan 2 (Alternatif ke 2$)$

A3 = Karyawan 3 (Alternatif ke 3)

A4 = Karyawan 4 (Alternatif ke 4)

A5 = Karyawan 5 (Alternatif ke 5)

b. Menentukan Kriteria yang digunakan untuk pemilihan karyawan terbaik. Kriteria yang digunakan sebanyak 5 kriteria yaitu : Absensi, Tanggungjawab, Kinerja, Attitude dan Inovatif. Dengan pemberian kode C01 untuk kriteria pertama. Dan untuk kode C05 merupakan kriteria terakhir. Berikut tabel dari kriteria yang digunakan untuk pemilihan karyawan terbaik seperti pada tabel 1.

Tabel 1 : Tabel Kriteria

\begin{tabular}{|l|l|l|l|}
\hline $\begin{array}{l}\text { Kode } \\
\text { Kriteria }\end{array}$ & $\begin{array}{l}\text { Nama } \\
\text { Kriteria }\end{array}$ & Attribut & Nilai \\
\hline C01 & Absensi & Benefit & 5 \\
\hline C02 & Tanggungjawab & Benfit & 5 \\
\hline C03 & Kinerja & Benefit & 5 \\
\hline C04 & Attitude & Benefit & 5 \\
\hline C05 & Inovatif & Benefit & 5 \\
\hline
\end{tabular}

c. Melakukan Penilaian kepada karyawan yang akan dipilih menjadi karyawan terbaik berdasarkan kriteria yang digunakan. 
Tabel 2 : Tabel Penilaian

\begin{tabular}{|l|l|l|l|l|l|}
\hline \multirow{2}{*}{ Alternatif } & \multicolumn{5}{|c|}{ Kode Kriteria } \\
\cline { 2 - 6 } & C01 & C02 & C03 & C04 & C05 \\
\hline A1 & 5 & 4 & 5 & 5 & 3 \\
\hline A2 & 4 & 4 & 4 & 5 & 4 \\
\hline A3 & 5 & 3 & 3 & 4 & 5 \\
\hline A4 & 4 & 5 & 4 & 5 & 5 \\
\hline A5 & 3 & 5 & 3 & 5 & 4 \\
\hline
\end{tabular}

Penilaian menggunakan skala $11 \quad-5$ dengan penjelasan sebagai berikut :

$5=$ Sangat Baik

$4=$ Baik

$3=$ Cukup

$2=$ Kurang

$1=$ Sangat Kurang

d. Proses Pembobotan, setelah melakukan penilaian maka tahap berikutnya adalah melakukan proses pembobotan adalah sebagai berikut :

$$
\begin{aligned}
& \mathrm{W} 1=\frac{5}{5+5+5+5+5}=\frac{5}{25}=0,2 \\
& \mathrm{~W} 2=\frac{5}{5+5+5+5+5}=\frac{5}{25}=0,2 \\
& \mathrm{~W} 3=\frac{5}{5+5+5+5+5}=\frac{5}{25}=0,2 \\
& \mathrm{~W} 4=\frac{5}{5+5+5+5+5}=\frac{5}{25}=0,2 \\
& \mathrm{~W} 5=\frac{5}{5+5+5+5+5}=\frac{5}{25}=0,2
\end{aligned}
$$

e. Menentukan Vector S

Setelah melakukan normalisasi bobot, maka langkah berikutnya adalah menghitung vector $\mathrm{S}$ dengan perhitungan sebagai berikut :

$$
\begin{aligned}
& \mathrm{S}_{1}=\left(5^{0,2}\right) \times\left(4^{0,2}\right) \times\left(5^{0,2}\right) \times\left(5^{0,2}\right) \times\left(3^{0,2}\right)=4.317 \\
& \mathrm{~S}_{2}=\left(4^{0,2}\right) \times\left(4^{0,2}\right) \times\left(4^{0,2}\right) \times\left(5^{0,2}\right) \times\left(4^{0,2}\right)=4.182 \\
& \mathrm{~S}_{3}=\left(5^{0,2}\right) \times\left(3^{0,2}\right) \times\left(3^{0,2}\right) \times\left(4^{0,2}\right) \times\left(5^{0,2}\right)=3.898 \\
& \mathrm{~S}_{2}=\left(4^{0,2}\right) \times\left(5^{0,2}\right) \times\left(4^{0,2}\right) \times\left(5^{0,2}\right) \times\left(5^{0,2}\right)=4.573 \\
& \mathrm{~S}_{3}=\left(3^{0,2}\right) \times\left(5^{0,2}\right) \times\left(3^{0,2}\right) \times\left(5^{0,2}\right) \times\left(4^{0,2}\right)=3.898
\end{aligned}
$$

f. Menentukan Vector V

Langkah berikutnya adalah menghitung vector $\mathrm{V}$ dengan perhitungan sebagai berikut :

$$
\begin{aligned}
& \mathrm{V} 1= \frac{4.317}{4.317+4.182+3.898+4.573+3.898}= \\
& \frac{4.317}{20.869}=0.207
\end{aligned}
$$

$$
\begin{gathered}
\mathrm{V} 2=\frac{4.182}{\frac{4.317+4.182+3.898+4.573+3.898}{20.869}=0.200}= \\
\end{gathered}
$$

$$
\begin{aligned}
& \mathrm{V} 3= \frac{3.898}{4.317+4.182+3.898+4.573+3.898}= \\
& \frac{3.898}{20.869}=0.187
\end{aligned}
$$

$$
\begin{gathered}
\mathrm{V} 4=\frac{4.573}{\frac{3.317+4.182+3.898+4.573+3.898}{20.869}=0.219}= \\
\mathrm{V} 5=\frac{3.898}{4.317+4.182+3.898+4.573+3.898}= \\
\frac{3.898}{20.869}=0.187
\end{gathered}
$$

g. Proses Perangkingan

Tahap terakhir adalah melakukan proses perangkingan sesuai dengan hasil akhir yang diperoleh pada vektor V seperti pada tabel 3 dibawah ini.

Tabel 3 : Tabel Perangkingan

\begin{tabular}{|l|l|l|l|}
\hline Alternatif & Nama Karyawan & Nilai & Rank \\
\hline A1 & Karyawan 1 & 0.207 & 2 \\
\hline A2 & Karyawan 2 & 0.200 & 3 \\
\hline A3 & Karyawan 3 & 0.187 & 4 \\
\hline A4 & Karyawan 4 & 0.219 & 1 \\
\hline A5 & Karyawan 5 & 0.187 & 4 \\
\hline
\end{tabular}

Berdasarkan tabel perangkingan maka dapat terlihat bahwa karyawan 4 mendapatkan nilai tertinggi yaitu 0.219 dan mendapatkan peringkat ke 1 . Sehingga karyawan 4 yang layak mendapatkan predikat sebagai karyawan terbaik. Sedangkan peringkat terakhir terdapat 2 nilai yang sama yaitu karyawan 4 dan karyawan 5.

\section{B. Perancangan Sistem}

a. Use Case Diagram

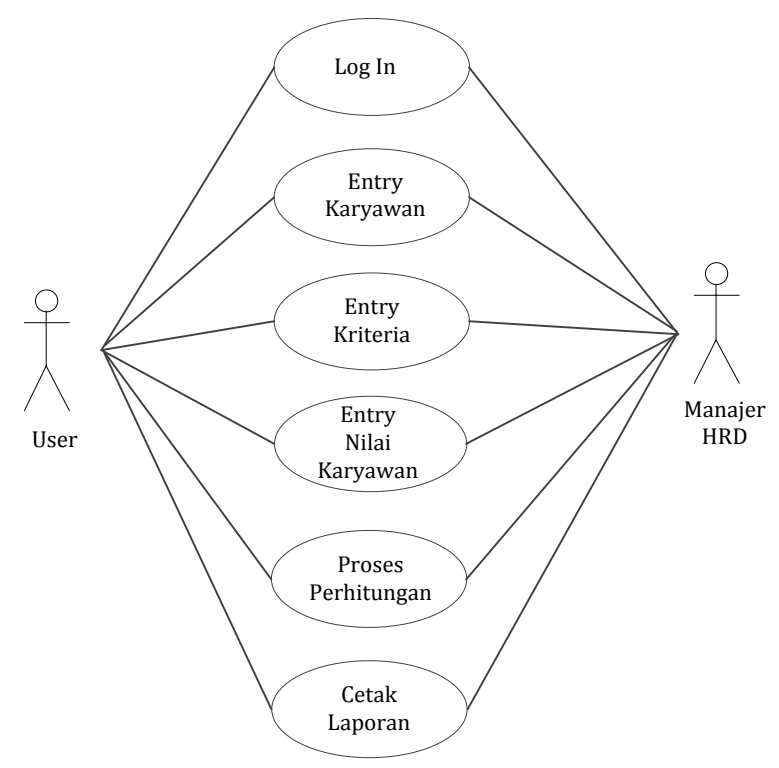

Gambar 1. Use Case Diagram 
b. Class Diagram

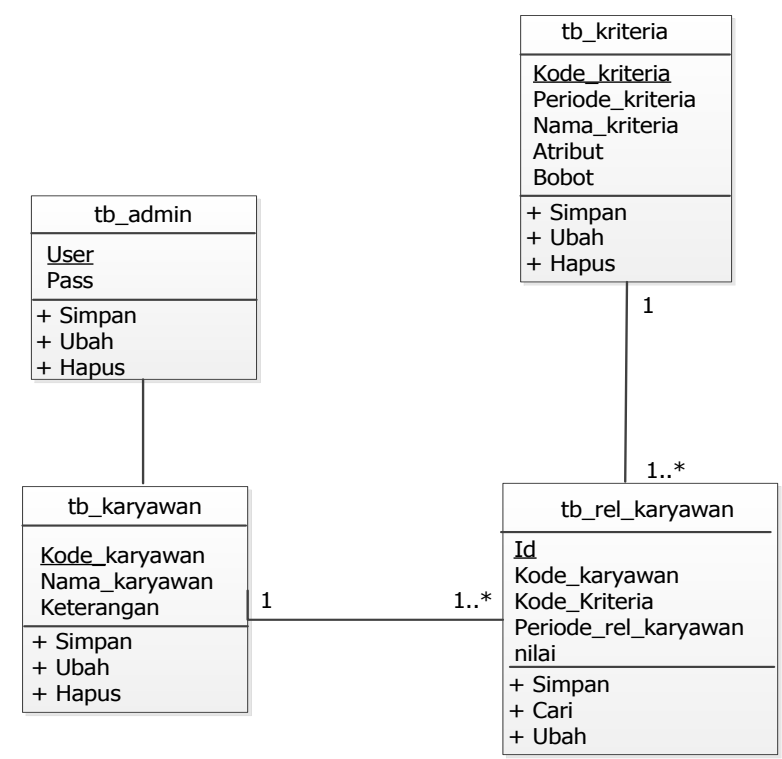

Gambar 2. Use Case Diagram

\section{Pengujian Aplikasi}

Berikut adalah hasil aplikasi penelitian yang telah dilakukan.

a. Entry Alternatif (karyawan yang akan dipilih menjadi karyawan terbaik)

Entry Data Karyawan

\begin{tabular}{|c|c|c|c|c|c|}
\hline \multicolumn{2}{|c|}{ Pencraicn. } & scai & \multicolumn{3}{|l|}{ + Tantanh } \\
\hline No & Koode & \multicolumn{2}{|c|}{ Nama kanazanan } & Keterangan & Aksi \\
\hline 1 & K001 & \multicolumn{2}{|c|}{ Wuchamrnad Fajif Faslah } & Kayalan Fieshyzaduate & 可金 \\
\hline 2 & K002 & \multicolumn{2}{|c|}{ Payij Pemana } & Serio letiviolik & 國 \\
\hline 3 & noos & \multicolumn{2}{|c|}{ Wharmad Divia llaradan } & & 可 \\
\hline 4 & K004 & \multicolumn{2}{|c|}{ 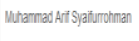 } & & 可 \\
\hline 5 & 1005 & \multicolumn{2}{|c|}{ Esa hara Pdera } & & 同 \\
\hline
\end{tabular}

Gambar 3. Entry Alternatif

b. Entry Kriteria

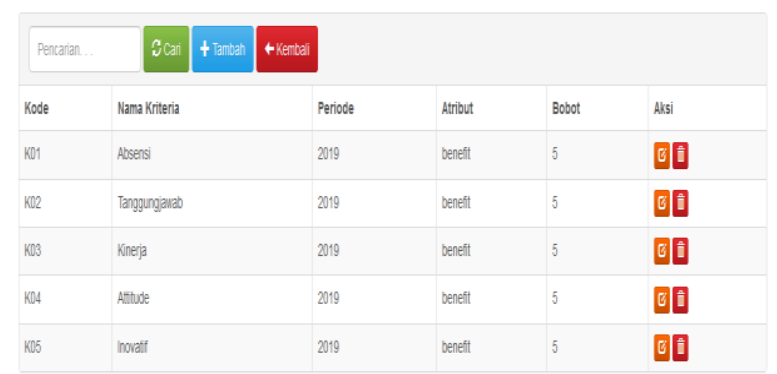

Gambar 4. Entry Kriteria c. Pengujian Entry Nilai Alternatif

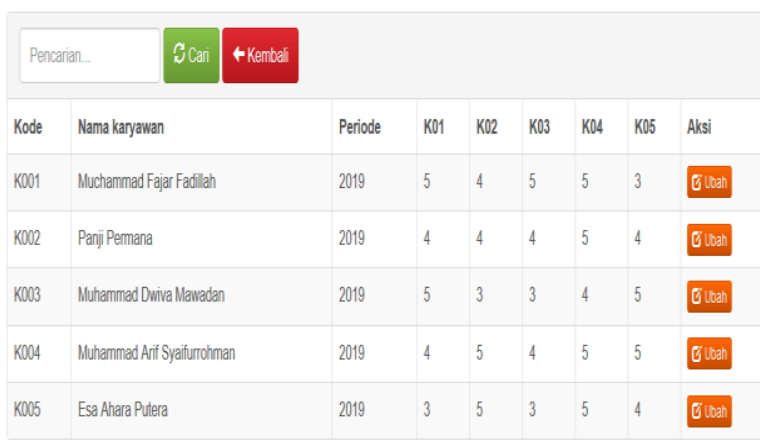

Gambar 5. Entry nilai alternatif

d. Proses Perhitungan

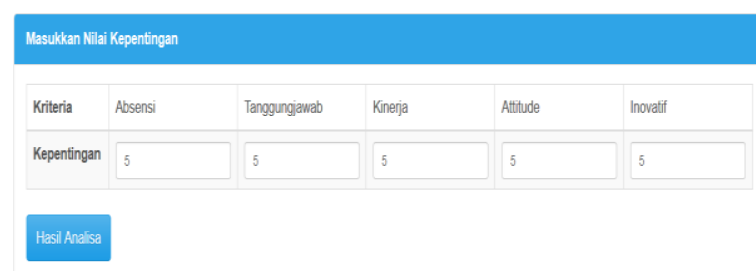

(a)

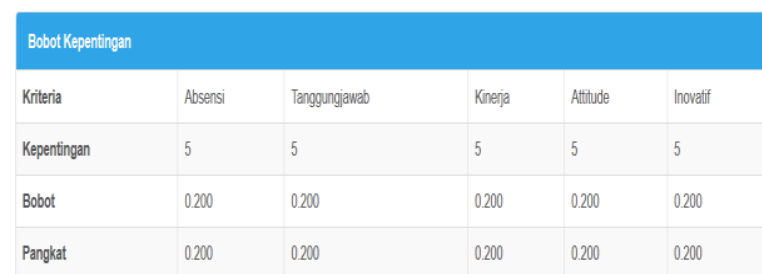

(b)

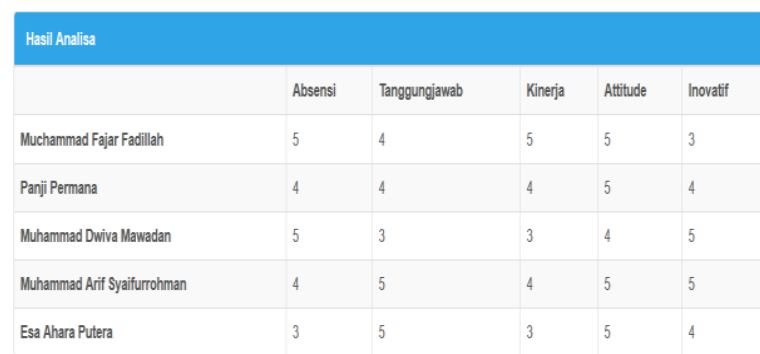

(c)

\section{Vetitor 8 \& VettorV}

\begin{tabular}{|c|c|c|}
\hline karyawan & Vektor S & Vektor V \\
\hline Muchammad Fajar Fadllah & 4.317 & 0.207 \\
\hline Panij Pemana & 4.183 & 0.200 \\
\hline Muhammad Dwva Mawadan & 3.898 & 0.187 \\
\hline Muhammad Aif Syäifurohman & 4.573 & 0.219 \\
\hline Esa Ahara Putera & 3.898 & 0.187 \\
\hline
\end{tabular}

(d) 


\begin{tabular}{|c|c|c|}
\hline \multicolumn{3}{|l|}{ Perangkingan } \\
\hline & Total & Rank \\
\hline KOO4 - Muhammad Arif Syaliurrohman & 0.219 & 1 \\
\hline KOO1 - Muchammad Fajar Fadillah & 0.207 & 2 \\
\hline K002 - Panji Permana & 0.2 & 3 \\
\hline K003 - Muhammad Dwiva Mawadan & 0.187 & 4 \\
\hline K005 - Esa Ahara Putera & 0.187 & 5 \\
\hline
\end{tabular}

(e)

Gambar 6. (a), (b), (c), (d), (e) Proses Perhitungan

e. Laporan Karyawan Terpilih

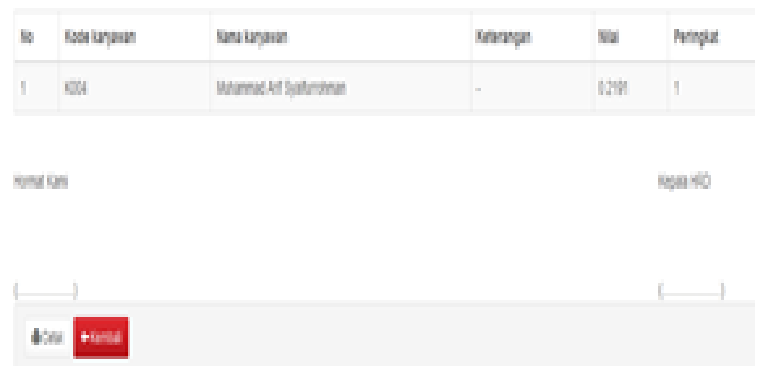

Gambar 7. Laporan Karyawan terpilih.

\section{KESIMPULAN}

Berdasarkan penelitian, implementasi dan pengujian, maka dapat diambil kesimpulan sebagai berikut :

1. Sistem pendukung keputusan karyawan terbaik dapat memberikan kemudahan bagi pihak pengambil keputusan dalam menentukan pilihan karyawan terbaik.

2. Pada aplikasi akan tampil hasil total penilaian beserta rangking dari masing-masing karyawan sehingga pihak pengambil keputusan dapat melihat nilai masing-masing karyawan.

3. Dalam penelitian selanjutnya dapat dilakukan pembobotan menggunakan metode AHP dan perhitungan nilai dapat menggunakan metode yang lain seperti TOPSIS, Profile Matching dan lain sebagainya.

\section{DAFTAR PUSTAKA}

[1] G. F. Lakoy, "Motivasi Kerja, Kompensasi, Pengembangan Karir Terhadap Kinerja Pegawai Pada Badan Penanggulangan Bencana Daerah Provinsi Sulawesi Utara," J. EMBA, vol. 1, no. 4, pp. 771-781, 2013.

[2] A. P. Mangkunegara, Evaluasi Kinerja Sumber Daya Manusia. Bandung: Refika Aditama, 2009.

[3] Mulyadi, Sistem Akuntansi Edisi Tiga. Jakarta: Salemba Empat, 2001.

[4] A. A. R. dan S. Haryadi, "Sistem Pendukung Keputusan Penilaian Kinerja Karyawan
Menggunakan Metode Weighted Product (WP) Di Pt Infomedia Solusi Humanika Bandung," $J$. LPKIA, vol. 1, no. 1, 2017.

[5] Khairina, "Implementasi Metode Weighted Product Untuk Aplikasi Pemilihan Smartphone Android," J. Infotel, vol. 8, no. 1, pp. 16-23, 2016.

[6] Sugiyono, Metode Penelitian Kuantitatif, Kualitatif dan R\&D. Bandung: PT Alfabet, 2016.

[7] S. Rudiarto, "Implementasi Algoritma K-Means," J. Ilmu Tek. Dan Komput., vol. 2, no. 1, pp. 1-8, 2018.

[8] N. Fartindyah dan Subiyanto "Sistem Pendukung Keputusan Peminatan Sma Menggunakan Metode Weighted Product (WP)," J. Kependidikan, vol. 44, no. 2, pp. 139-145, 2014.

[9] A. Rim, S. Manik, B. Nurhadiyono, and Y. Rahayu, "Implementasi Metode Weighted Product ( WP ) Dalam Sistem Pendukung Keputusan Untuk Menyeleksi Penerima Beras Masyarakat Miskin ( RASKIN )," Techno.COM, vol. 14, no. 2, pp. 109-114, 2015.

[10] Kusumadewi, Fuzzy Multi- Atrribute Decision Making (Fuzzy MADM). Yogyakarta: Graha Ilmu, 2006. 